\title{
Presentation Special Issue Opening methodology issues for Mobilities in the Mediterranean ${ }^{1}$ Presentación Monográfico Apertura de problemas metodológicos de las movilidades en el Mediterráneo
}

\section{Natalia Ribas-Mateos ${ }^{1}$ (coordinator)}

${ }^{1}$ Researcher, Universitat Autònoma de Barcelona, Spain.

Correspondence: Natalia Ribas-Mateos. C/Olles 1, 17004 Girona, Spain. E-mail: mazo@arquired.es

(C) Revista Internacional de Estudios Migratorios. CEMyRI. UAL (España)

\footnotetext{
${ }^{1}$ This monograph is a result of a doctoral atelier: Methodological Challenge: Studying Mobilities in the Mediterranean, Caiat (Tetouan province), 23- 24 November 2015. With the participation of Carlota Solé, Sònia Parela, Laura Feliu, Natalia Ribas-Mateos as mentors. And with the participation of Francisco Belhorma, Chiara Denaro, Maria Rocco, Cristina Fuentes, Alicia Español, Thales Speroni, Clara Piqueras, Rocío Fajardo and Zakaria Aissa, as doctoral students. We thank the collaboration of Daniel Pinto for the logistics of the seminar. As for the publication we thank the constant engagement of Pablo Pumares and the team of this journal.
} 
Firstly, we have to start thinking about the topic itself. Finding a topic, discussing various topics of research, finding a case, delimitating a case-study and their possible methodology which is open for discussion. Through innovative and interdisciplinary theoretically and empirically embedded research, there is a need to open new and critical doors, in which it is paramount to explore the processes of reconfiguration of mobilities today taking into account the different repositioning of actors in a local, regional and global space. In short, it is vital to dissect the inter-scale context in the EU and in the Mediterranean through adoption of a challenging and pioneering multidisciplinary perspective.

I propose to introduce this monograph by simply opening "Pandora's box" regarding methodology issues, which is what one is facing when looking at what is happening in the field of research. In order to give some sense to it all, I thought that a good starting point would be by locating the place -cartography, the Mediterranean (here some parts of it)-, the time -other historical moments- and moving concepts -in constant reinterpretation-.

Still, this particular moment traces back a recent phase of migration policies which recalls the so-called Europe's refugee crisis, which has become aggravated since the first string of humanitarian maritime catastrophe on the island of Lampedusa (Italy) in 2013, which has put many questions on the table concerning concepts, categories, scales and emergency border politics. Globally speaking, one of the major impacts of the "European crisis" is the reconfiguration of mobilities, accompanied by the problem of inhospitable policies towards migrants/refugees at different levels (international/regional/national/local) and different types of humanitarian responses.

This is a difficult mapping as it is constantly shifting due to new arrivals and the modification of transit, stopping and waiting. A mapping waiting to be determined by the configuration and reconfiguration of historical and contemporary relations regarding such mobilities. While taking on the challenge of capturing the contemporary moment, this paper also reflects on the longue durée, the historical background of mobilities in the Mediterranean, memory embedded for example in the reconfiguration of past mobilities. This Mediterranean setting has implications for at least three main foci: intra-EU and out of EU detention zones, border zones; and cities. At the core of this mapping and conceptual setting, Fortress Europe, which was established during the early 1990s, is represented as a point of departure.

As regarding borders, Soriano and Fajardo (in this volume) are able to tackle several structural contradictions when we study the relations between migrations and borders: the universalisation of rights, vis-a-vis border controlling, the asymmetry in freedom of movement, proliferation of borders, and porousness of borders.

Secondly, we would have to start thinking about what type of methodology and what type of techniques (quantitative and qualitative) are available for research, as well as planning ahead, deciding a framework for the planned fieldwork to what to collect or what not to collect. And of course, thinking about the research question and 
problematising it, what kind of hypothesis and of research questions are selected based on prior ideas about the research area.

Thirdly, we have to think about the background, how I define the importance of my research, how I justify it. We need then to choose the background for our research: theory. A theoretical orientation is a general attitude about how a phenomenon is to be explained. Different theoretical approaches provide different styles of explanation. Was a theoretical perspective identified? The thinking and theoretical perspective of the researcher can influence the study. The researcher should know something conceptually of the phenomenon of interest, and should state the theoretical perspective up front. We need to work on the background of our research, the literature, reading the relevant literature from other societies (or your own) in order to sharpen one's understanding or preparing for comparison. Thus selecting the right literature on issues like mobilities and transnationalism prepares theoretically for fieldwork.

Regarding the general mapping and most common background for this issue, Español et al. (in this volume), do map very well the area mostly covered in this volume as they refer also to techniques regarding the construction of the biographical interview. For them, the border has been and still is a source of conflict between Spain and Morocco, and the people suffer the consequences. Similarly, the vigilant state in which Morocco lives can make the people suspicious about the intentions of the research and its objectives, affecting the confidence with which these people could approach the researchers. Therefore, for them, the task as social scientists is to earn the trust of people, breaking away from the differential power that is set in the relationship itself. They also develop an autobiographical semi-structured interview to study selfconstruction. For them, this interview explores the influence of the most important aspects of the border scenario in the self-construction, and in the personal meanings of this experience. This reveals how the structural aspects that make up this reality and the construction of personal meanings are related.

Fourthly, we have to think about the conceptual structure of any research, which always includes these focal points: What is already known about this issue in particular or the area in general? What concepts are used or disputed about? What has not been studied yet? What are the still open questions? Which theories are used and discussed in this area? What are the theoretical debates or controversies in this field? What are the methodological traditions and alternatives here? Which are the sociopolitical and ethical issues which arise as part of the research process?

As a first conceptual challenge, Piqueras (in this issue) shows how, under the expansion of the new dynamics of mobility observed, return migration has gained increased interest by articulating a theoretical transnational approach (with policies and voluntary return programmes for Colombian migrants), considering the way in which return migration is conceived in terms of management and temporality, and identifying the returnees' profile considered in these policies. The aim is to overcome an analysis focused only on a territory, seeking to overcome the methodological nationalism view 
and avoiding this way a nation-state-centred methodology, avoiding then the linear conception of the migration process. From this theoretical perspective, Piqueras argues that the mobility of people comprises complex circuits where the return should be treated as one more stage of the migration process. Therefore, she addresses the phenomenon from a point of view that deconstructs the classical categories of migration, and which allows us to consider more complex forms of mobility that are excluded from the temporary dichotomous approaches, such as the circular or pendulum migration, or the re-migrations to third countries. She focuses on frequent practices and links that are sustained over time across borders, distinguishing different forms of transnationalism that have been defined depending on who promotes it, distinguishing between the practices driven "from below" -activities carried out by the migrants- and "from above" -initiatives promoted by the governments of origin.

Following on this conceptual problematisation regarding transnationalism, Speroni (in this volume) examines the analyses of transnational social protection, highlighting the relevance of migrants' agency. He follows then a framework whioch emphasise the new features and dynamics of the international flow of goods, capital, suggesting a reconsideration of classic and substantial sociological concepts and frameworks. The multiplication of social life scales, produces a complexification of problems of social justice and social inequality which makes him examine the strategies of transnational social protection manifested in the interface between informal (interpersonal networks) and formal social protection (provided by national states and organisations), not only through their objective elements (multi-sited resources and services), but also by their subjective aspects (actors' meanings and institutional normative concepts). All of it, with the comprehension of the meanings that motivate different modes of use of these resources, by mobile and non-mobile actors. He then shows the empirical research on the ways of "doing family", which are transformed and diversified. These families have complex lives, marked by the use of international mobility as a resource for social protection, to "make a living" and to promote the care of particularly those most vulnerable, such as children, the elderly, and the sick. Then, the key is the care circulation approach which conceives that the exchange of care in families is reciprocal, asymmetrical, and oriented by a norm of generalised reciprocity.

Then, we have to include data. Finding the data and distinguishing the type of data available and distinguishing between internal and external sources of data and information. When using interviews we have to consider the forms of sampling in qualitative research, which is purposeful, and the process used to select participants should be clearly described. Purposeful sampling selects participants for a specific reason e.g., age, culture, experience, not randomly. On the other hand, if the purpose is to explore an issue in-depth, 'key informant' approach may be appropriate.

When using qualitative interviews we put emphasis on listening and following the direction of the participant/informant. We can conduct pilot interviews first, in order to test our questions. A variety of open-ended questions are chosen to elicit the most information possible in the time available. Fuentes (in this volume) illustrates it after 
considering the intensification of cross-border transport of people and commodities that takes place at the Tarajal border. Looking at trans-boundary women, most of whom are domestic workers, sex workers and traders, the focus is set on the latter. With respect to differences regarding their journey, interviews are heavily mobile as five main routes are used. (i) Women who live in Tetouan start their day at 6 a.m. Small groups of porteadoras meet and walk together on their way to catch a taxi that will take them to the border; they wait until they can cross the border and go to the industrial park of Tarajal. They take the goods through the Biutz bridge, give the goods to the buyers in Moroccan territory in a plain near the border, and after that, at 12 a.m., they take another taxi back to Tetouan. They earn 8 to 12 euro a day, depending on the weight of their fardos and the value of the goods. (ii) Porteadoras from Martil and (iii) porteadoras from Rincon (M'diq), who follow the same process as the Tetouani porteadoras. (iv) Porteadoras from Castillejos (Fnideq), a village that is about two kilometres away from the border.

Barros also uses the idea of constant movement in order to conduct his interviews, following the territorialisation of the export-oriented industrialisation in Morocco and migration routes in Spain. Such interviews cover many key topics as: socio-occupational experience in Spain, which addresses issues such as the career path of the interviewee after migration, current occupational status (both of the interviewee and of their family/network), their sending (or not sending) remittances, their legal status in Spain, or their personal view on the Spanish labour market during the socioeconomic crisis.

Belhorma (in this volume) unveils through interviews the real participation of women in the informal sector, and the implications of gender inequality in the informal employment by examining the presence of women in the shadow economy and by exploring their contribution to the national economy. She assesses the profiles of women in the informal sector activities in the city of Fez, which is done through the examination of their socio-demographic and professional characteristics. It will also deal with their main motives and reasons to end up working in self-employed activities. She adds a mixed methods approach to generate credible findings via both quantitative and qualitative methods of research. In this regard, most of the data collection using quantitative methods was based upon qualitative explanations and all the qualitative data were described numerically. Through such search she shows how government statistics should be revised in order to include women labour force for the sake of having credible statistics of women in total labour force. This would oblige the government to acknowledge the existence of the informal sector, its contribution to the formal economy and its workers.

As regarding ethnographic research, it is an eclectic methodological choice which privileges engaged research and scientific reflexivity, integrating a contextually rich and nuanced type of qualitative technique, in which fine grained daily interactions are the lifeblood of data. Many researchers are using now multilocal ethnography: a wide extension of places and routes. In a way, one might argue, that the term 
'multilocal' is a little misleading, for what current multilocal projects have in common is that they draw on the same problem, same formulation of a topic, which is significantly translocal, not to be confined within some single place. Paths of interdependence of grounded theory and ethnography is underlined in this volume by Association Assafron in the frame of the current so-called refugee crisis in Southern European countries, and bringing empirical references from previous research, concerning the right to asylum in the border zones and the transit mobility of refugees from Southern European countries to the Northern ones, the article explores three methodological challenges that qualitative research encounters, such as grounded theory and ethnography, applied to the study of refugees' transit mobilities. The so-called ethical dilemma that the observation of and interaction with seaborne refugees, who are in many cases still traumatised by the journey at sea, can produce; secondly, the difficulties of carrying out a 'long-term observation' of people in transit, who are often in a 'grey zone' between legality and illegality, and do not have the 'time' or the intention to build relationships; thirdly, the uncomfortable role of the ethnographer as a 'detached observer' in such a context and the need to renegotiate his/her identity.

Last but not least, I would include ethics. The complex relation between theory and participative methodology has been at the core of many essays concerning qualitative research methods. But nowadays, we have to add new challenges, one of the main ones is the one concerning ethics. The first challenge, concerning the ethic dilemma, is generated by the addressing of vulnerability and trauma during the semiparticipant observation and the in-depth interviews. Nevertheless, as S. underlines in the following lines (in Asaffron's article), through refugees' narratives the researcher is only able to grasp a little part of the entire traumatic experience that fleeing from war and then the seaborne migration produce:

"Those who are not rich, who don't know how many months they will need to collect enough money to leave Syria, can only go to Europe by sea. And there, on that route, either they die, or they arrive, with a trauma that they will bring with them for almost the rest of their life. If I think about my case...my wife, my children, they are still completely traumatised by the sea. Now I have only told you about travel. How it was, how we ran into the water, how we were crammed on the boat, how we were dying and how we were saved. But it remains only a tale. Living it is always something entirely different." [Interview with S., Syrian refugee from Dara'a, 18 June, Catania Train Station, Assafron's article]. 